\title{
IMPACT OF NITROGEN REGIME ON FATTY ACID PROFILES THAT PRODUCED BY DESMODESMUS QUADRICAUDATUS AND CHLORELLA SP.
}

\author{
Hesham M. Shafik ${ }^{1,2 *}$, Marwa G. Saad ${ }^{1}$ and Hamed A. El-Serehy ${ }^{3}$ \\ ${ }^{1}$ Botany Department, Faculty of Science, Port-Said University, \\ Port-Said, 42536, Egypt; drmgs84@yahoo.com \\ ${ }^{2}$ Limnoecological Research Group of the Hungarian Academy of \\ Sciences, Veszprém, Hungary, Egyeteme st.10, \\ heshamshafik@aloms.uni-pannon.hu \\ ${ }^{3}$ College of Science, King Saud University, Riyadh 11451, P.O. Box 2455, \\ Saudi Arabia,hel_serehy@yahoo.com
}

\begin{abstract}
Microalgae have emerged as one of the most promising sources for fatty acids production. Since the various fatty acid profiles (chain length, degree of unsaturation, and branching of the chain) of the different sources influence biodiesel fuel properties, it is important to possess data on how the presence of $\mathrm{NaNO}_{3}$ as nitrogen source can influence the profile of produced fatty acids from algae. The fatty acid profiles of Desmodesmus quadricaudatus and Chlorella sp. were detected in batch cultures experiments. BG-11 nitrogen free medium or the medium contained $1.5 \mathrm{~g} \mathrm{NaNO}_{3} \mathrm{l}^{-1}$ were used in this investigation. At late stationary growth phase in nitrogen free medium, Chlorella sp. produced $58.39 \%$ saturated fatty acids and $41.60 \%$ unsaturated fatty acids. While in medium contained $1.5 \mathrm{~g} \mathrm{NaNO}_{3} \mathrm{I}^{-1}$ produced $62.08 \%$ saturated fatty acids and $37.92 \%$ unsaturated fatty acids. In nitrogen free media $D$. quadricaudatus produced $66.92 \%$ saturated fatty acids and $33.07 \%$ unsaturated fatty acids. While in cultures contained $1.5 \mathrm{~g} \mathrm{NaNO}_{3} \mathrm{l}^{-1}$ produced $51.62 \%$ saturated fatty acids and $48.37 \%$ unsaturated fatty acids. The fatty acid profile of Chlorella sp. that isolated from Egyptian water body and grown in nitrogen free media may suitable for biodiesel production. The results discussed and compared to fatty acids profiles produce by other algal species.
\end{abstract}

Keywords: Batch cultures, Chlorella sp., Desmodesmus quadricaudatus, Fatty acid, Nitrogen regime.

\section{Introduction}

Microalgae have significant environmental and commercial importance. They are not only sources of food for humans and animals, but are also the sources of a wide range of chemical compounds used in industry, food technology 
and pharmaceuticals. They are microscopic, photosynthetic renewable resources with the potential to produce large quantities of lipids (fats and oils). Hossain $\boldsymbol{e t}$ al. (2008) stated that it is very simple to extract oil from algae.

As demonstrated (Gouveia and Oliveira, 2009) microalgae have high photosynthetic efficiency, fast growth rate, high biomass productivities and highest $\mathrm{CO}_{2}$ fixation and $\mathrm{O}_{2}$ production rate. Also, it can be grown in variable climates, non-arable land including marginal areas unsuitable for agricultural purpose, no seasonal production, thrive in non-portable water, use less water and do not compete with food crop culture. Many microalgae are capable of accumulating a large amount of lipids in the cells (U. S. Department of Energy, 1998). On average, the lipid contents typically range from 10 to $30 \%$ of dry weight. Algae grown to late logarithmic growth phase typically contain 30-40\% proteins, 10- 20\% lipids and 5-15\% carbohydrates (Barsanti and Gualtieri, 2006). Mata et al. (2010) showed that depending on the specific algae species and their cultivation conditions, however, micro-algal lipid production might range widely from 2 to $75 \%$. In some extreme cases, it can reach $70 \%-90 \%$ of dry weight (Chisti, 2007; Li et al., 2008). Nitrate and silicate stress has effect on the lipid content in a variety of phytoplankton (U. S. Department of Energy, 1998). Illman et al. (2000) studied five strains of the green alga Chlorella, and reported an increase in lipid content in all five strains when grown in low-nitrogen media. In the case of Chlorella emersonii and Chlorella minutissima, 63 and $56 \%$ oil were obtained in low-nitrogen media compared to 29 and $31 \%$ in high-nitrogen media respectively. Scragg et al. (2002) supported these findings by also finding that the lipid content increased in low-N medium for Chlorella strains.

Dayananda et al. (2007) illustrated that the content of lipid, carbohydrate and proteins varies from species to species. Most common algae like Chlorella, Crypthecodinium, Cylindrotheca, Dunaliella, Isochrysis, Nannochloris, Nannochloropsis, Neochloris, Nitzschia, Phaeodactylum, Porphyridium, Schizochytrium, Tetraselmis, Botryococcus braunii and Scenedesmus species have oil levels between 20 and 50\% but higher productivities can be reached. Under adverse growth conditions such as nitrogen limitation, low temperature, high light intensity, high salt concentration and high iron concentration the lipid content in some of micro-algae increased (Hsieh and $\mathbf{W u}, \mathbf{2 0 0 9})$. This may due to alteration in their lipid biosynthesis pathways towards the formation and accumulation of neutral lipids (Hu et al., 2008). Lipid accumulation was up to $80 \%$ of dry cell weight and mainly in the form of triacylglycerol due to the shift in metabolism from membrane lipid synthesis to the storage of neutral lipids tri-acyl-glycerides (TAG). Paulson and Ginder (2007) concluded that algal lipids occur in cells predominantly as either polar lipids (mostly in membranes) or lipid bodies, typically in the form of tri-acyl-glycerides (TAG). The latter are accumulated in large amounts during photosynthesis as a mechanism to endure adverse environmental conditions. Polar lipids usually contain polyunsaturated fatty acids 
(PUFA), which are long-chained, but have good fluidity properties. TAG in lipid storage bodies typically contain mostly saturated fatty acids (SFA) that have a high-energy contents, but, depending on the fatty acid profile of the algal strain, may lack fluidity under cold conditions. Provided the algal oil is low enough in moisture and free fatty acids, biodiesel is typically produced from TAG with methanol using base-catalyzed transesterification (Schuchard et al., 1998). Fatty acids are converted as source of energy. The idea of using microalgae as a source of fatty acids which may be change to fuel is not new (Kapdan and Kargi, 2006; Meier, 1955). Changing of fatty acids to fatty acid alkyl esters, fatty acid methyl esters (FAME), or long-chain mono alkyl esters are the main key for biodiesel production from algae (Thomas, 2006). Triglycerides in oil are transesterificated with a lower alcohol in the presence of an acidic or a basic catalyst into the corresponding long-chain fatty acid alkyl esters (Tyagi et al., 2010).

The accumulation of lipid begins as the cells enter stationary phase and cell division ceases; the timing of this event would be different for individual cells within a population. Nutrient limitation, generally nitrate or silica, can trigger lipid accumulation in microalgae. Nutrient deprivation can cause a decrease in cell division, which presumably results in "targeting" of excess fixed carbon into storage lipids. In green algae, lipid accumulation is induced among others by $\mathrm{N}$ starvation. $\mathrm{N}$ is a component of many cellular molecules, and $\mathrm{N}$ limitation would induce a complex response, affecting photosynthesis, protein and nucleic acid synthesis, and other biochemical processes (U. S. Department of Energy, 1998). Shafik (2003) and Kenesi et al. (2009) studied the effect of nitrogen forms and its concentration on growth rate, cell composition and morphology.

This study aimed to show the effects of absent and presence of nitrogen on fatty acid profiles produced by Desmodesmus quadricaudatus and Chlorella sp. isolated from Egyptian water. Moreover, compere the fatty acids profiles of studded species to that used for biofuel production in some literature.

\section{Materials and Methods}

\section{Isolation and identification of algal strains}

Microalgae samples were collected from variety of freshwater bodies at Port-Said City in summer 2009. Chlorella sp. and Desmodesmus quadricaudatus (Turpin) "Bréb." (this name is currently regarded as a synonym of Scenedesmus quadricauda (Turpin) Brébisson) were isolated from these samples. Initial strain isolations were performed by streaking out samples onto $1.5 \%$ agar plates containing BG-11 medium. Each strain was examined using binocular light microscopy (SME-F4D, Rating: 85 V to 265 V, 50/60 Hz, Halogen lamp: 60 V 20 W, Delay-action fuse: 1 A) to look for morphological differences and to confirm species identify according to Smith (2010).

Egyptian J. of Phycol. Vol. 15, 2014 


\section{Cultivation and experiments design}

The used BG-11 medium (Barsanti and Gualtieri, 2006) contained $\left(\mathrm{gl}^{-1}\right)$, $\mathrm{NaNO}_{3}, 1.5 ; \mathrm{K}_{2} \mathrm{HPO}_{4} \cdot 3 \mathrm{H}_{2} \mathrm{O}, 0.04 ; \mathrm{MgSO}_{4} \cdot 7 \mathrm{H}_{2} \mathrm{O}, 0.075 ; \mathrm{CaCl}_{2} \cdot 2 \mathrm{H}_{2} \mathrm{O}, 0.036$; citric acid, 0.006, ferric ammonium citrate, 0.006; $\mathrm{Na}_{2}$ EDTA, 0.001; $\mathrm{Na}_{2} \mathrm{CO}_{3}$, 0.02 . In addition to $1 \mathrm{ml}$ of trace metal solution (including $\mathrm{H}_{3} \mathrm{BO}_{3} ; 2.86 \mathrm{~g}$, $\mathrm{MnCl}_{2} \bullet 4 \mathrm{H}_{2} \mathrm{O} ; 1.81 \mathrm{~g}, \quad \mathrm{ZnSO}_{4} \cdot 7 \mathrm{H}_{2} \mathrm{O} ; 0.222 \mathrm{~g}, \quad \mathrm{Na}_{2} \mathrm{MoO}_{4} \cdot 2 \mathrm{H}_{2} \mathrm{O} ; 0.390 \mathrm{~g}$, $\mathrm{CuSO}_{4} \cdot 5 \mathrm{H}_{2} \mathrm{O} ; 79 \mathrm{mg}$ and $\left.\mathrm{Co}\left(\mathrm{NO}_{3}\right)_{2} \bullet 6 \mathrm{H}_{2} \mathrm{O} ; 49.4 \mathrm{mg} \mathrm{l}^{-1}\right)$ was used to determine the growth and fatty acid production. However, $\mathrm{NaNO}_{3}$ was omitted from the medium in case of $\mathrm{N}$ free medium experiments. The $\mathrm{pH}$ of all cultures was 7.4.

All cultures were incubated at room temperature of $27 \pm 1^{\circ} \mathrm{C}$ and continuous light using two fluorescent tubes of TL-D $18 \mathrm{~W}$ (Snow white Extreme cool Day light E9, made in Poland) and bubbled with sterilized air.

Cultures of both strains was started by transferring of a colony of the species in question with the help of platinum wire, respectively into 50, 100, 250, 500 , and $1000 \mathrm{ml}$ flasks containing BG-11 medium with $1.5 \mathrm{~g} \mathrm{NaNO}_{3} \mathrm{l}^{-1}$. This culture used as stock culture in experiments.

New cultures for each species ran in fresh BG-11 medium contained $1.5 \mathrm{~g}$ $\mathrm{NaNO}_{3} \mathrm{l}^{-1}$. Samples were daily harvested to measure growth and maximum growth rates as turbidity and chlorophyll-a content.

To determine fatty acid composition, a certain volume of the stock culture were inoculated to fresh medium containing $1.5 \mathrm{~g} \mathrm{NaNO}_{3} \mathrm{l}^{-1}$ (starter culture). After depletion of nitrate from the culture suspension, the culture was divided into two new culture flasks. One of the flask contained fresh medium with $1.5 \mathrm{~g}$ $\mathrm{NaNO}_{3} \mathrm{l}^{-1}$ (diluted culture with $\mathrm{N}$ ), while the other was diluted with combined nitrogen free medium (diluted culture without $\mathrm{N}$ ). At late stationary growth phase, the cells were harvested and processed to determine fatty acid profiles. Chlorophyll-a, turbidity and nitrate were measured for the new cultures. All cultures ran in three replicates.

\section{Measurement of growth and estimation of algal biomass}

Turbidity at $750 \mathrm{~nm}$ and chlorophyll a were used for measurement and calculation of algal growth and growth rate. Chlorophyll a content was measured according to Iwamura et al. (1970) at 653, 666 and 750nm using 6800 Double beam UV/Visible Spectrophotometer, Jenway, made in England.

Growth rate ( $\mu, d-1)$ were calculated according to Eq. (1) (Andersen, 2005):

specific growth rate; $\mu=\ln (\mathrm{N} 1-\mathrm{N} 2) /(\mathrm{t} 1-\mathrm{t} 2)$

Where $\mathrm{N} 1$ and $\mathrm{N} 2$ are biomass at time ${ }^{\mathrm{t} 1}$ and ${ }^{\mathrm{t} 2}$, respectively. 


\section{Nitrate concentration determination}

The concentrations of nitrate in the media were determined with spectrophotometer (6405 UV/Visible Spectrophotometer, Jenway, made in England) according to Cataldo et al. (1975).

\section{Biomass collection}

The colonies of $D$. quadricaudatus were self-settled by stopped culture aeration for 2 hours then the settled biomass was collected and dried at $30^{\circ} \mathrm{C}$ for 2 days. Alum (Aluminum Sulphate Octadecahydrate; $\mathrm{Al}_{2}\left(\mathrm{SO}_{4}\right)_{3} .18 \mathrm{H}_{2} \mathrm{O}$, molar mass $666.42 \mathrm{~g} / \mathrm{mol}$ ), as a chemical flocculent was added to the culture of Chlorella $\mathrm{sp}$. for settling the cells then the biomass was harvested and dried at $30^{\circ} \mathrm{C}$ for 2 days. The lowest amount of alum that makes the best precipitation of Chlorella sp. determined by adding $0,1.8,3.0,4.8,6.0,7.8,9.0$ and $10.8 \mathrm{mmol}$ alum $\mathrm{l}^{-1}$ to the culture and mixed for 2 min thereafter left to settling.

\section{Oil extraction}

Dried algae (2g) were extracted all night in hexane/ether solution $(1 / 1$, $\mathrm{V} / \mathrm{V})$ to extract oil. The mixture was kept for $24 \mathrm{~h}$ for settling. This step repeated until the extract became hyaline (Basova, 2005).

\section{Evaporation}

The extract was evaporated in vacuum to release hexane and ether solutions using rotary evaporator (Diagonal Condenser-RE300, PTFE/glass liquid pathway for chemical inertness, sparkless induction motor, long life graphite impregnated PTFE vacuum seal, efficient flask and vapor tube ejection system, speed range 20 to $190 \mathrm{rpm}$, Vacuum $1 \mathrm{~mm} \mathrm{Hg}$, made in U.K.) according to (Hossain et al., 2008).

\section{Fatty Acid Analysis}

The extracted oil was methyled according to (Luddy et al., 1960). The fatty acids were measured using Gas Chromatography (Perkin Elmer Auto system XL) equipped with Flame Ionization Detector (FID), fused silica capillary column DB$5\left(60 \mathrm{~m} * 0.32 \mathrm{~mm}\right.$ i.d.), oven temperature was maintained initially at $150^{\circ} \mathrm{C}$ and programmed from $150^{\circ} \mathrm{C}$ to $240^{\circ} \mathrm{C}$ at rate $3^{\circ} \mathrm{C} / \mathrm{min}$, held at $240^{\circ} \mathrm{C}$ for $30 \mathrm{~min}$. Injector temperature was $230^{\circ} \mathrm{C}$. Detector temperature was $250^{\circ} \mathrm{C}$ and carrier gas was Helium with flow rate of $1 \mathrm{ml} / \mathrm{min}$ ). The used standard was 3-Nonanone.

\section{Results}

A strain of Chlorella sp. and D. quadricaudatus were isolated, identified and grown in BG-11 medium. The growth of both species was investigated as turbidity and chlorophyll a concentration. The cultures entered stationary growth phase after $72 \mathrm{~h}$ (Fig. 1). The maximum growths rates $(\mu)$, measured from chlorophyll a concentrations were 3.02 and $2.96 \mathrm{~d}^{-1}$ for Chlorella sp. and D. quadricaudatus, respectively. 


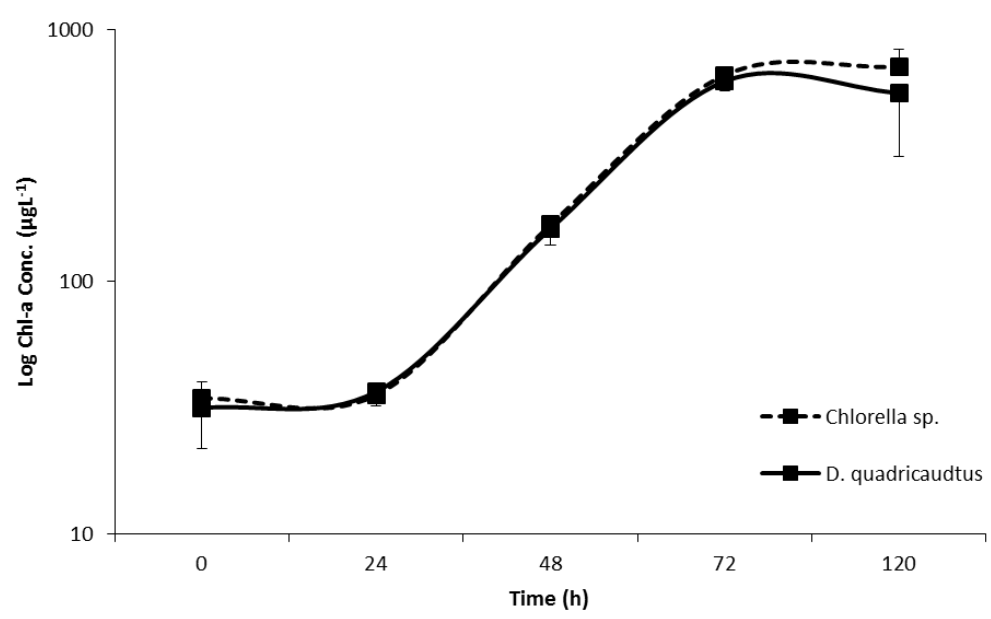

Figure (1): Growth curve of Chlorella sp. and D. quadricaudatus measured as Chlorophyll a at room temperature of $27 \pm 1^{\circ} \mathrm{C}$, with continuous light. Standard error bars for Chlorella sp. shows in plus direction and for D. quadricaudatus in minus direction.

Growth of Chlorella sp. as turbidity and chlorophyll-a concentration in the started culture, which contained $1.5 \mathrm{~g} \mathrm{NaNO}_{3} \mathrm{l}^{-1}$ until day 6 of the experiment is shown in Figs. 2 and 3. On day 6, nitrate concentration was undetected in culture suspension (Fig. 6), and then the culture was divided to two equal volumes and diluted by fresh medium (diluted culture). One culture group was grown in culture medium containing $\mathrm{NaNO}_{3}$ and the other in nitrogen free medium. The growth of algae is shown in Fig 2 and 3.

In case of $D$. quadricaudatus, nitrogen was undetected in the culture suspension of starter culture on day 12 (Fig. 6). At that day, the same procedure was done as same as the culture of Chlorella sp.

In diluted cultures with $1.5 \mathrm{~g} \mathrm{NaNO}_{3} \mathrm{l}^{-1}$, Chlorella sp. reach a maximum chlorophyll a concentration of $10650 \pm 54 \mu \mathrm{g} \mathrm{l}^{-1}$ and turbidity was $1.25 \pm 0.003$ after 12 days of dilution. While $D$. quadricaudatus reach a maximum chlorophylla concentration of $2207 \pm 68 \mu \mathrm{g} \mathrm{l}^{-1}$ and turbidity of $1.01 \pm 0.006$ after 3 and 6 days of dilution for chlorophyll a and turbidity, respectively (Figs. 4 and 5).

In diluted cultures of $\mathrm{N}$ free medium, Chlorella sp. reach a maximum chlorophyll-a concentration of $3288 \pm 35.45 \mu \mathrm{g} \mathrm{l}^{-1}$ and the turbidity was $0.50 \pm$ 0.008 after 9 days of dilution (Figs. 2 and 3). While D. quadricaudatus reach a maximum chlorophyll-a concentration of $1342 \pm 34 \mu \mathrm{g} \mathrm{l}^{-1}$ and turbidity of $0.50 \pm$ 0.008 after 12 days of dilution (Figs. 4 and 5). 


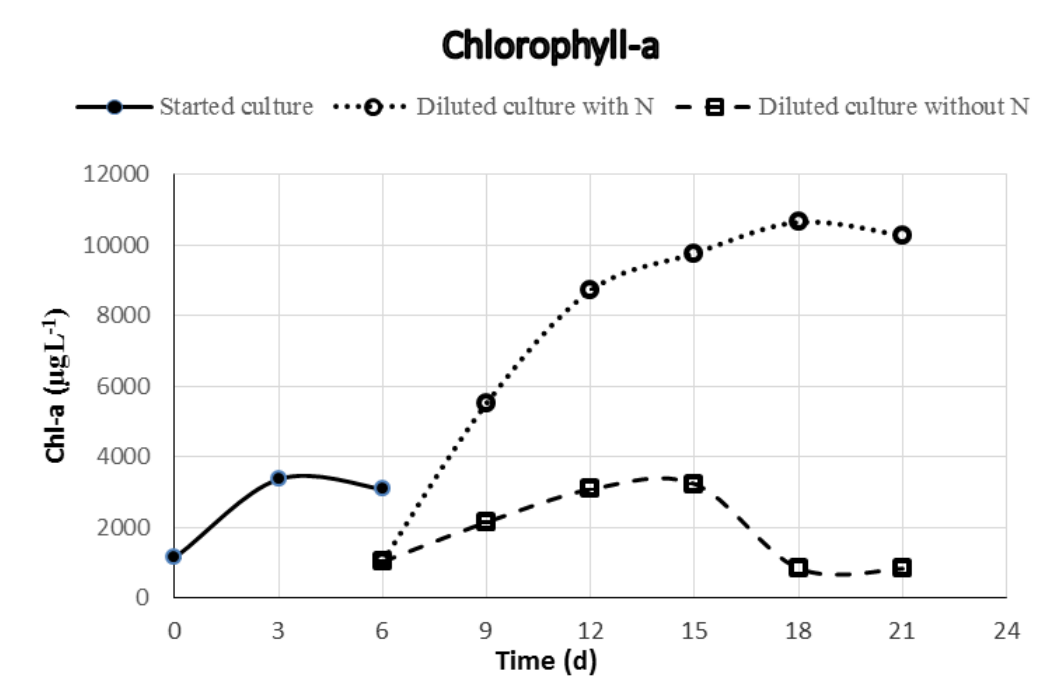

Figure (2): Growth of Chlorella sp. measured as Chlorophyll a at room temperature of $27 \pm 1^{\circ} \mathrm{C}$, with continuous light.

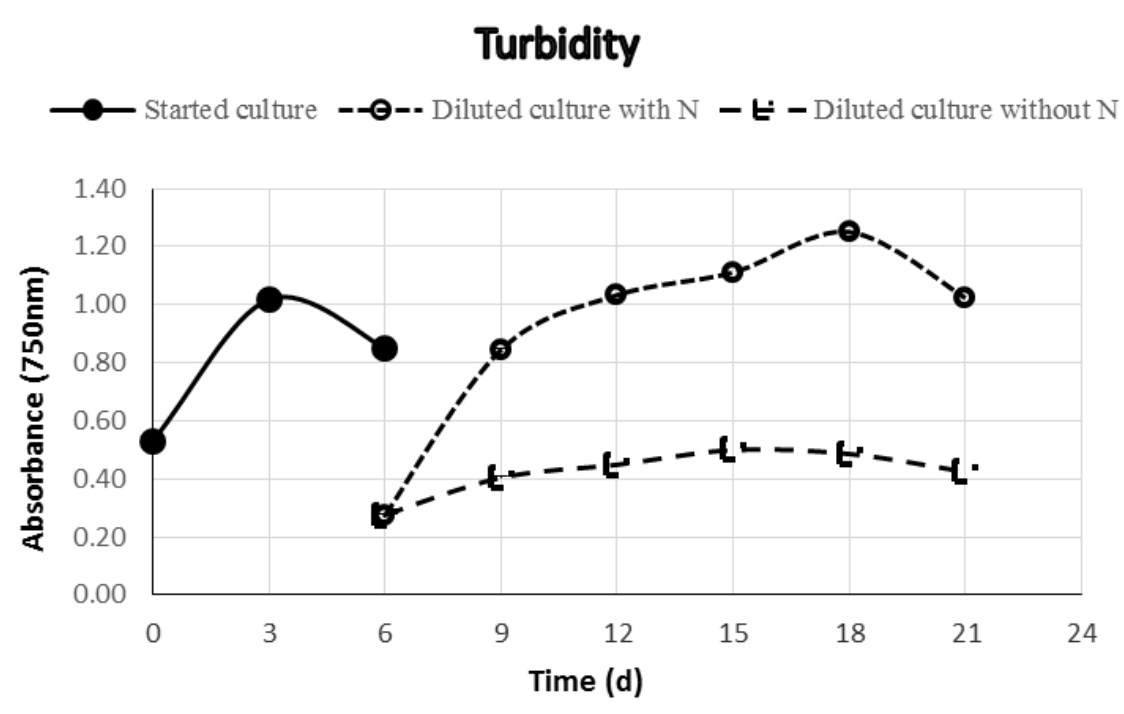

Figure (3): Growth of Chlorella sp. measured as Turbidity at room temperature of $27 \pm 1^{\circ} \mathrm{C}$, with continuous light. 


\section{Chlorophyll-a}

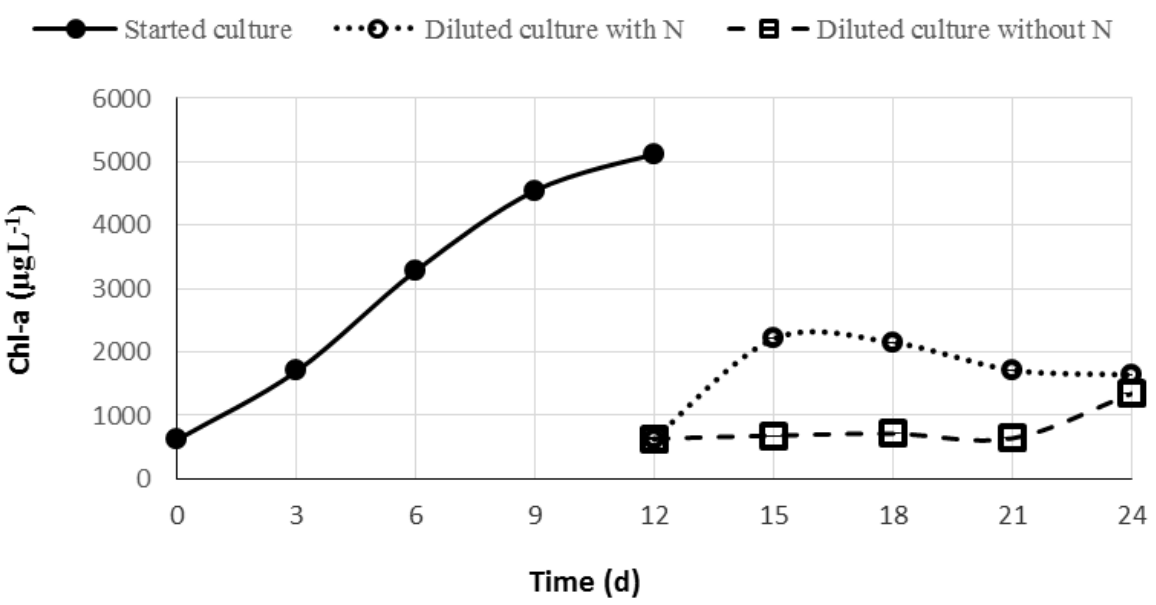

Figure (4): Growth of D. quadricaudatus measured as Chlorophyll a at room temperature of $27 \pm 1^{\circ} \mathrm{C}$, with continuous light.

\section{Turbidity}

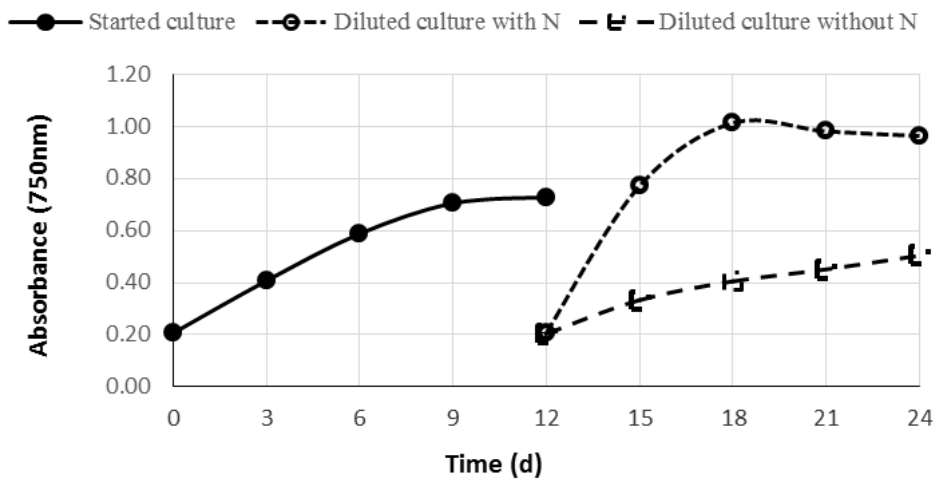

Figure (5): Growth of D. quadricaudatus measured as Turbidity at room temperature of $27 \pm 1^{\circ} \mathrm{C}$, with continuous light. 


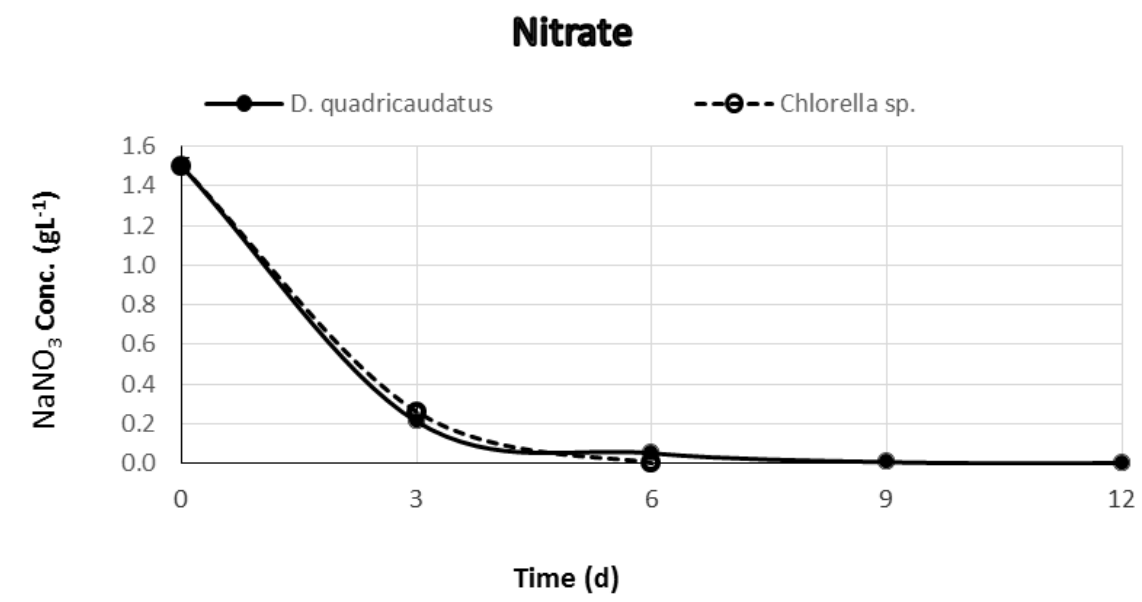

Figure (6): Sodium Nitrate concentration in Chlorella sp. and $D$.

quadricaudatus cultures measured at room temperature of $27 \pm 1^{\circ} \mathrm{C}$, with continuous light.

At late stationary phase, samples were harvested from each culture for fatty acids analysis.

Different concentrations of alum were tested to detect the minimum alum concentration for complete precipitation of Chlorella cells. This concentration was $1.8 \mathrm{mmol}$ alum after 10 minutes mixing. D. quadricaudatus colonies were self-precipitated.

Chlorella sp. produced $58.39 \%$ saturated fatty acids which were myristic acid (C14.0), palmitic acid (C16.0) and stearic acid (C18.0) and 41.60\% unsaturated fatty acids which were palmitoleic acid (C16.1), oleic acid (C18.1), linoleic acid (C18.2), linolenic acid (C18.3) and eicosapentaenoic acid (C20.5) in the nitrogen free media (Table 1). While in medium contained1.5g $\mathrm{NaNO}_{3} \mathrm{l}^{-1}$ Chlorella sp. produced $62.08 \%$ saturated fatty acids (palmitic acid, C16.0 and stearic acid, C18.0) and 37.92\% unsaturated fatty acids "linoleic acid, C18.2 and eicosapentaenoic acid, C20.5; Table 1".

D. quadricaudatus produced $66.92 \%$ saturated fatty acids (palmitic acid, C16.0 and stearic acid, C18.0) and 33.07\% unsaturated fatty acids (palmitoleic acid, C16.1, oleic acid, C18.1 and linoleic acid, C18.2) in nitrogen free media. While in medium contained $1.5 \mathrm{~g} \mathrm{NaNO}_{3} 1^{-1}$ produced $51.62 \%$ saturated fatty acids (palmitic acid, C16.0 and stearic acid, C18.0) and 48.37\% unsaturated fatty acids "oleic acid, C18.1 and eicosapentaenoic acid, C20.5" (Table 1).

Table 1 summarize the changes of fatty acids profiles of Chlorella sp. and D. quadricaudatus with nitrogen regime and the percent of fatty acid composition for both species. So, the type and amount of fatty acids more or less affected by mode of nitrogen supply. Fig. 7 shows the fatty acid profile as saturated fatty Egyptian J. of Phycol. Vol. 15, 2014 
acids (SFA), monounsaturated fatty acids (MUFA) and polyunsaturated fatty acids (PUFA) of Chlorella sp. and D. quadricaudatus grown in present of nitrogen or in nitrogen free media.

Table 1. Fatty acid profile (\% of total fattv acids) of Chlorella sp. and $D$. quadricaudatus measured by GC.

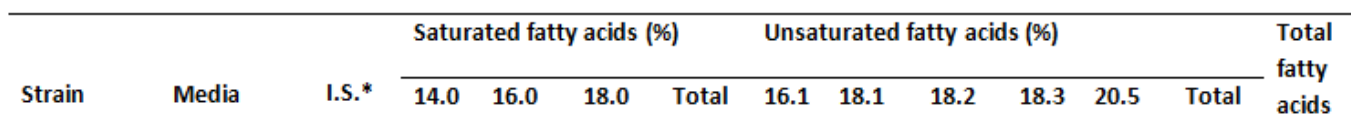

(\%)

\begin{tabular}{|c|c|c|c|c|c|c|c|c|c|c|c|c|c|}
\hline \multirow{3}{*}{$\begin{array}{l}\text { Chlorella } \\
\text { sp. }\end{array}$} & $1.5 \mathrm{~g}$ & $\mathrm{~N}^{*}$ & $\ldots$ & 14.39 & 47.69 & 62.08 & $\cdots$ & $\ldots$ & 22.22 & $\ldots$ & 15.70 & 37.92 & 100 \\
\hline & $\mathrm{NaNO}_{3} \mathrm{~L}^{-1}$ & & & & & & & & & & & & \\
\hline & $\begin{array}{l}\text { Nitrogen- } \\
\text { free media }\end{array}$ & 0.01 & 1.04 & 50.03 & 7.32 & 58.39 & 1.65 & 12.79 & 15.57 & 8.79 & 2.80 & 41.60 & 100 \\
\hline \multirow{3}{*}{$\begin{array}{l}D . \\
\text { quadricaud } \\
\text { atus }\end{array}$} & $1.5 \mathrm{~g}$ & 0.01 & $\ldots$ & 18.19 & 33.43 & 51.62 & .... & 35.02 & $\ldots$ & .... & 13.35 & 48.37 & 100 \\
\hline & $\mathrm{NaNO}_{3} \mathrm{~L}^{-1}$ & & & & & & & & & & & & \\
\hline & $\begin{array}{l}\text { Nitrogen- } \\
\text { free media }\end{array}$ & 0.01 & $\ldots$ & 60.15 & 6.77 & 66.92 & 5.42 & 6.65 & 21.00 & $\cdots$ & $\ldots$ & 33.07 & 100 \\
\hline
\end{tabular}

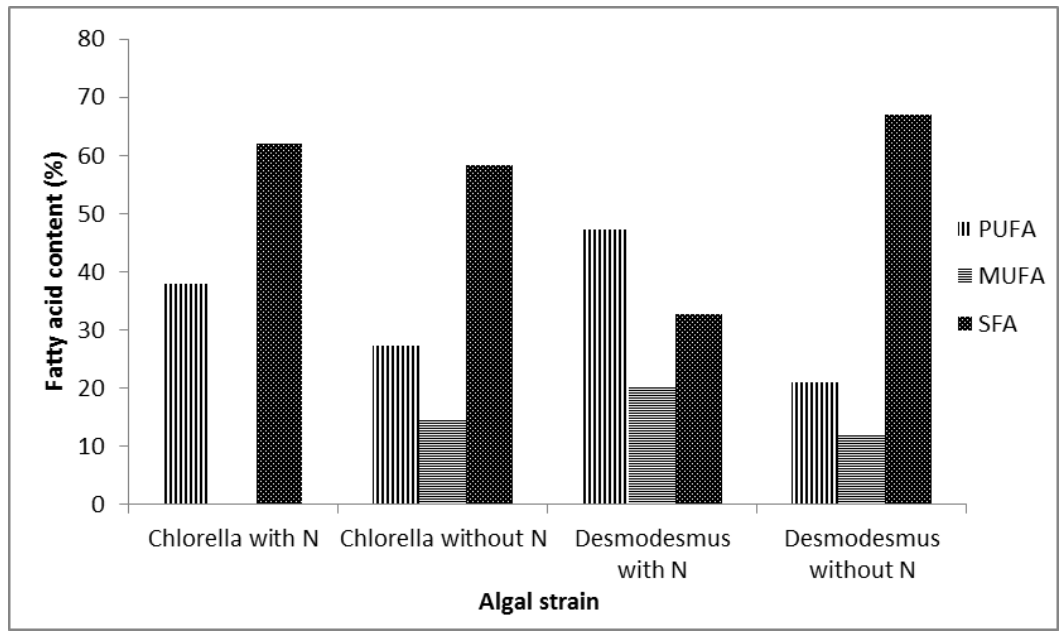

Figure (7): Fatty acid profile of $D$. quadricaudatus and Chlorella sp. grown in BG-11 medium contended $1.5 \mathrm{~g} \mathrm{NaNO}{ }_{3} l^{-1}$ or in nitrogen free medium. SFA, saturated fatty acids; MUFA, monounsaturated fatty acids; PUFA, polyunsaturated fatty acids. 


\section{Discussion}

The choice of microalgae for fatty acids profiles and for biofuel production requires a balance between species that grow quickly against those which produce oil in large quantities. Therefore, Chlorella sp. and D. quadricaudatus were choice in this investigation, where both species have high maximum growth rate of 3.02 and $2.96 \mathrm{~d}^{-1}$, respectively. These maximum growth rates are significant factor for algal mass production (Shafik, 1991). Shafik (1991) recorded a maximum growth rate for Scenedesmus spinosus (newly, Desmodesmus spinosus) of $3.0 \mathrm{~d}^{-1}$ which is close to the obtained data. High maximum growth rate is an indication for favor growth conditions. Jena et al. (2012) obtained that the specific growth rate for both Chlorella and Scenedesmus sp. was $0.38 \mathrm{~d}^{-1}$. Further, given that most oil is produced during a "starvation" or "stress" phase, successful fatty acids production will require species that can be reliably manipulated, are tolerant of a range of environmental perturbations - natural and operator induced and are able to "recover" from these alterations and continue growing (Jiang $\boldsymbol{e t}$ al., 2012). It is important to possess data on how the nitrogen starvation can influence the profile of produced fatty acids so the various fatty acid profiles of the different sources can used for production such as biodiesel fuel.

One of the most important processes for studying the fatty acid profiles is the harvesting of algal yield. Algae can be harvested using micro-screens, by centrifugation, or by flocculation. Froth flotation is another method to harvest algae. Interrupting the carbon dioxide supply to an algal culture system could cause algae to flocculate on its own, which is called "autoflocculation". Harvesting by sedimentation (bioflocculation) has promise, but was strain specific and was increased by N limitation (U. S. Department of Energy, 1998). Harvesting capability is an important feature of microalgae fatty acids analysis (Christenson and Sims, 2011; Scholz et al., 2011). Park et al. (2011) showed that many microalgae settle under adverse conditions, and this could be tested under small-scale conditions. Some strains of Chlorella did not settle (U. S. Department of Energy, 1998). Here the tested Chlorella sp. was not selfprecipitated therefore, different concentrations of alum were used to detect the lowest alum concentration that precipitate most of Chlorella cells. This concentration was $1.8 \mathrm{mmol} \mathrm{Al}_{2}(\mathrm{SO} 4)_{3} .18 \mathrm{H}_{2} \mathrm{O}$. However, D. quadricaudatus was self-precipitated and easily harvested.

Basova (2005) showed the major fatty acids of different algal groups. Basova (2005) reported that the lipids of many microalgae species are rich in polyunsaturated fatty acids (PUFAs).

Jena et al. (2012) obtained that Scenedesmus sp. produced 36.5\% saturated fatty acid and $63.5 \%$ unsaturated fatty acid. Scenedesmus sp. contains high amount of palmitic acid $(16: 0,30.3 \%)$ and the unsaturated fatty acid represented by linoleic acid $(\mathrm{C} 18: 2,21.1 \%)$ and oleic acid $(18: 1,17.5 \%)$. Other long chain 
PUFA are present in small amount. These properties make Scenedesmus sp. suitable for biodiesel production. Basova (2005) also, reported that Chlorella sp. produced $34.0 \%$ saturated fatty acid and $66.0 \%$ unsaturated fatty acid, higher amount of UFA was present among which PUFA content is $35 \%$. Among unsaturated fatty acids, linolenic acid was the most dominant fatty acid (26.3\%) Besides the PUFA, oleic acid $(18: 1,15.1 \%)$ and palmitic acid $(16: 0,24.5 \%)$ are principal fatty acids (Table 2).

Table 2. Comparison of fatty acid composition (\% of total fatty acids) of some microalgal strain grow at stationary phase

\begin{tabular}{r|rrrrrr}
\hline Fatty & $C 1$ & $S 1$ & $C 2$ & $C 3$ & $D 1$ & $D 2$ \\
acids & & & & & & \\
& & & $+\mathrm{N}$ & $-\mathrm{N}$ & $+\mathrm{N}$ & $-\mathrm{N}$ \\
\hline 12.0 & 0.3 & - & - & - & - & - \\
14.0 & 0.9 & 0.7 & - & 1.04 & - & - \\
15.0 & 0.3 & 0.3 & - & - & - & - \\
16.0 & 24.5 & 30.3 & 14.39 & 50.03 & 18.19 & 60.15 \\
16.1 & 4.9 & 6.5 & - & 1.65 & - & 5.42 \\
16.2 & 1.3 & 5.7 & - & - & - & - \\
16.3 & - & - & - & - & - & - \\
16.4 & - & - & - & - & - & - \\
17.0 & 2.1 & 2.6 & - & - & - & - \\
17.1 & 10.0 & 2.7 & - & - & - & - \\
18.0 & 2.5 & 1.2 & 47.69 & 7.32 & 33.43 & 6.77 \\
18.1 & 15.1 & 17.5 & - & 12.79 & 35.02 & 6.65 \\
18.2 & 5.7 & 21.1 & 22.22 & 15.57 & - & 21.0 \\
18.3 & 26.3 & 9.2 & - & 8.79 & - & - \\
18.4 & - & - & - & - & - & - \\
20.0 & 0.4 & 0.1 & - & - & - & - \\
20.1 & 0.4 & - & - & - & - & - \\
20.2 & 0.3 & 0.3 & - & - & - & - \\
20.3 & 0.3 & 0.1 & - & - & - & - \\
20.4 & - & - & - & - & - & - \\
20.5 & 1.1 & 0.8 & 15.70 & 2.80 & 13.35 & - \\
21.0 & 1.1 & - & - & - & - & - \\
22.0 & 1.1 & 0.6 & - & - & - & - \\
22.1 & 0.6 & - & - & - & - & - \\
24.0 & 0.8 & 0.3 & - & - & - & - \\
SFA & 34.0 & 36.5 & 62.08 & 58.39 & 51.62 & 66.92 \\
USFA & 66.0 & 63.5 & 37.92 & 41.60 & 48.37 & 33.07 \\
\hline
\end{tabular}


Rodolfi et al. (2009) concluded that culturing and environmental conditions affect the productivity of algae, lipid yield and fatty acid compositions. In a pilot study of Chlorella sp. the high growth rates could be achieved by increasing nitrogen concentrations while lipid accumulation could be achieved by nitrogen starvation. Thomas et al. (1984) recorded that at low concentration of nitrogen Chlorella synthesized saturated (16:0) and monounsaturated (18:1) fatty acids, whereas at high nitrogen concentrations the 16:2, 16:3, 16:4 and 18:2 fatty acids predominated. Chlorella sp. is an oleaginous alga, that has a potential application, is currently used at pilot experimental level for biodiesel production is commercially produced and available in large quantities. Lee et al. (2011) stated that saturated and unsaturated fatty acids like palmitic acid (C16:0), stearic acid (C18:0), oleic acid (C18:1), linoleic acid (C18:2), and linolenic acid (C18:3) are common fatty acids for biodiesel production. Thomas et al. (1984) reported that significant fatty acids used for biodiesel production, include saturated fatty acids and polyunsaturated fatty acids (PUFAs), such as C14:0, C16:0, C16:1, C18:0, C18:1, C18:2, C18:3 fatty acids. In our results, Chlorella sp. in nitrogen free media tended to produce the fatty acid pattern is a diverse, saturated (C14.0, C16.0 and C18.0) and unsaturated fatty acids (C16.1, C18.1, C18.2, C18.3 and C20.5). D. quadricaudatus produced unsaturated fatty acids (C16.1, C18.1 and C18.2) and saturated fatty acids are represented by (C16.0 and C18.0) in nitrogen free media (Tables 1, 2). Accordingly, both species that isolated from Egyptian water body may be suitable for biodiesel production, where it contains all these types of fatty acids.

In Table 2: C1, S1 presented Chlorella sp. and Scenedesmus sp. after Jena et al. (2012). In the present study, $\mathrm{C} 2$ indicates Chlorella sp. grown in culture content $1.5 \mathrm{~g} \mathrm{NaNO}_{3} \mathrm{l}^{-1}, \mathrm{C} 3$ indicates Chlorella sp. grown in nitrogen free media, $\mathrm{D} 1$ indicates $D$. quadricaudatus grown in culture content $1.5 \mathrm{~g} \mathrm{NaNO}_{3} \mathrm{l}^{-1}$ and $\mathrm{D} 2$ indicates $D$. quadricaudatus grown in nitrogen free media.

\section{References}

Andersen, R.A. (2005). Algal Culturing Techniques. first ed. Phycol. Soc. Am., ELSEVIER Academic Press.

Barsanti, L. and Gualtieri, P. (2006). Algae Anatomy, Biochemistry and Biotechnology. Boca Raton, London New York.

Basova, M.M. (2005). Fatty acid composition of lipids in microalgae. Int. J. Algae., 7: 33 - 57.

Cataldo, D.A.; Maroona, M.; Schradera, L.E. and Youngsa, V.L. (1975). Rapid colorimetric determination of nitrate in plant tissues by nitration of salicylic acid. Commun. Soil Sci. Plant Anal., 6: 71 - 80.

Chisti, Y. (2007). Biodiesel from Microalgae. Biotechnol. Adv., 25: 294 - 306. 
Christenson, L. and Sims, R. (2011). Production and harvesting of microalgae for wastewater treatment, biofuels, and bioproducts. Biotechnol. Adv., 29: $686-702$.

Dayananda, C.; Sarada, R.; Kumar, V. and Ravishankar, G.A. (2007). Isolation, characterization of hydrocarbon producing green microalgae Botryococcus braunii from Indian fresh-water bodies. Electron $J$ Biotechnol., 10: 78 - 91.

Gouveia, L. and Oliveira, A.C. (2009). Microalgae as a raw material for biofuel production. J. Ind Microbiol Biotechnol., 36: 269 - 274.

Hossain, A.B.M.; Salleh, A.; Boyce, A.N.; Chowdhury, P. and Naqiuddin, M. (2008). Biodiesel Fuel Production from Algae as Renewable Energy. Am. J. Biochem. Biotechnol., 4: 250 - 254.

Hsieh, C.H. and Wu, W.T. (2009). Cultivation of microalgae for oil production with a cultivation strategy of urea limitation. Bioresour. Technol., 100: 3921 - 3926.

Hu, Q.; Sommerfeld, M.; Jarvis, E.; Ghirardi, M.; Posewitz, M.; Seibert, M. and Darzins, A. (2008). Microalgal triacyl-glycerols as feedstocks for biofuel production: Perspectives and advances. Plant J., 54: 621 - 639 .

Illman, A.M.; Scragg, A.H. and Shales, S.W. (2000). Increase in Chlorella strains calorific values when grown in low nitrogen medium. Enzym. Microb. Technol., 27: 631 - 635.

Iwamura, T.; Nagai, H. and Ichimura, S. (1970). Improved methods for determining contents of chlorophyll, protein, ribonucleic acid, and deoxyribonucleic acid in planktonic populations. Int. Res. Ges. Hydrobiol., 55: 131 - 147.

Jena, J.; Nayak, M.; Panda, H.S.; Pradhan, N.; Sarika, C.; Panda, P.K.; Rao, B.; Prasad, B.N. and Sukla, L.B. (2012). Microalgae of Odisha coast as a potential source for biodiesel production. World Environ., 2: 11 - 16.

Jiang, Y.; Yoshida, T. and Quigg, A. (2012). Photosynthetic performance, lipid production and biomass composition in response to nitrogen limitation in marine microalgae. Plant Physiol. Biochem., 54: 70 - 77.

Kapdan, I.K. and Kargi, F. (2006). Bio-hydrogen production from waste materials. Enzyme Microb. Tech., 38: 569 - 82.

Kenesi, G.; Shafik, H.M.; Kovács, A.W.; Herodek, S. and Présing, M. (2009). Effect of nitrogen forms on growth, cell composition and $\mathrm{N}_{2}$ fixation of Cylindrospermopsis raciborskii in phosphorus-limited chemostat cultures. Hydrobiologia., 623: 191 - 202. 
Lee, S.J.; Go, S.; Jeong, G.T. and Kim, S.K. (2011). Oil production from five marine microalgae for the production of biodiesel. Biotechnol. Bioprocess Eng., 16: 561 - 566.

Li, Y.; Horseman, M.; Wang, B.; Wu, N. and Lan, C.Q. (2008). Effects of nitrogen sources on cell growth and lipid accumulation of green alga Neochloris oleoabundans. Appl. Microbiol. Biotechnol., 81: 629 - 636.

Luddy, F.E.; Beerford, R.A. and Riemenschneider, R.W. (1960). Direct conversion of lipid component to their fatty acid methyl ester. J. Am. Oil Chem. Soc., 37: 447 - 451.

Mata, T.M.; Martins, A.A. and Caetano, N.S. (2010). Microalgae for biodiesel production and other applications: A review. Renew Sust. Energ. Rev., 14: 217 - 232.

Meier, R.L. (1955). Biological cycles in the transformation of solar energy into useful fuels. In: Solar Energy Res., Madison University Wisconsin Press. pp: 179 - 183.

Park, J.B.K.; Craggs, R.J. and Shilton, A.N. (2011). Recycling algae to improve species control and harvest efficiency from a high rate algal pond. Water Res., 45: 6637 - 6649.

Paulson, N.D. and Ginder, R.D. (2007). The growth and direction of biodiesel industry in the united states; Center for Agricultural and Rural Development: Iowa State University. IA, USA, pp: 3.

Rodolfi, L.; Chini Zittelli, G.; Bassi, N.; Padovani, G.; Biondi, N.; Bonini, G. and Tredici, M.R. (2009). Microalgae for oil: Strain selection, induction of lipid synthesis and outdoor mass cultivation in a low-cost photobioreactor. Biotechnol. Bioeng., 102: 100 - 112.

Scholz, M.; Hoshino, T.; Johnson, D.; Riley, M.R. and Cuello, J. (2011). Flocculation of wall-deficient cells of Chlamydomonas reinhardtii mutant cw15 by calcium and methanol. Biomass Bioenergy., 35: 4835 - $\mathbf{4 8 4 0}$.

Schuchard, U.; Serchelia, R. and Vargas, R. (1998). Transesterification of Vegetable Oils: a Review. J. Braz. Chem. Soc., 9: 199 - 210.

Scragg, A.H.; Illman, A.M.; Carden, A. and Shales, S.W. (2002). Growth of microalgae with increased calorific values in a tubular bioreactor. Biomass Bioenergy., 23: 67 - 73.

Shafik, H.M. (1991). Growth, Nutrient uptake and competition of algae of Lake Balaton in flow-through cultures, Unpublished dissertation in partial fulfilment of the requirements for the degree of Doctor of Philosophy, Hungarian Academy of Sciences, Hungary. pp: 121. 
Shafik, H.M. (2003). Morphological characteristics of Cylindrospermopsis raciborskii (Wołoszyńska) Seenayya et Subba Raju in laboratory cultures. Acta Biologica Hungarica., 54: 121 - 36.

Smith, T.E. (2010). Revised list of algae from Arkansas, U.S.A. and new additions. Int. J. Algae., 12: 230 - 256.

Thomas, F.R. (2006). Algae for liquid fuel production. Oakv. Permaculture Center. Permaculture Activist., 59: 1 - 2.

Thomas, W.H.; Tornabene, T.G. and Weissman, J. (1984). Screening for lipid yielding microalgae: Activities for 1983; Solar Energy Research Institute: Golden, Colorado, USA.

Tyagi, O.S.; Atray, N., Kumar, B. and Datta, A. (2010). Production, Characterization and development of standards for biodiesel - A Review. J. Metrology Soc. India., 25: 197 - 218.

U. S. Department of Energy (1998). A Look Back at the U.S. Department of Energy' Aquatic Species Program: Biodiesel from Algae. N .R. E. L. 
تأثير النيتروجين على صورة الحمض الدهني المنتج من طحلب ديسموديسمس كو ادريكودس و طحلب الكلوريلا

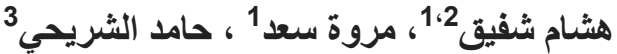 \\ 1- 1 قسم النبات، كلية العلوم، جامعة بورسعيد، بورسعيد

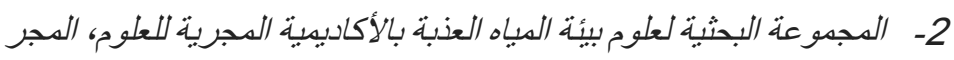

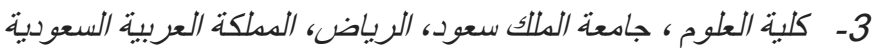

ظهرت الطحالب الدقيقة باعتبار هاواحدة من أكثر المصادر الواعدة لإنتاج الأحماض الاهنية. يعتبر

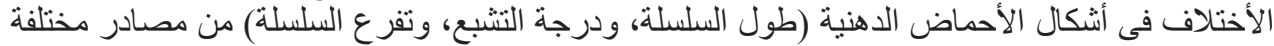

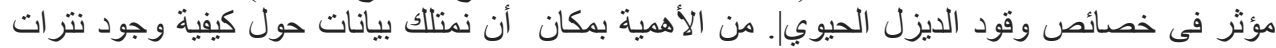

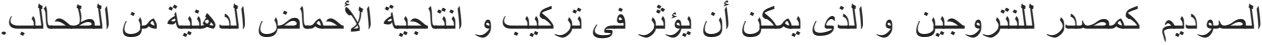

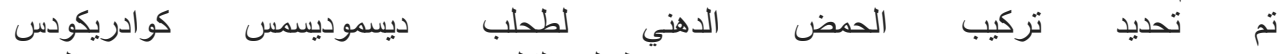
(Chlorella sp.) و نوع من طحلب الكلوريلا (Desmodesmus quadricaudatus)

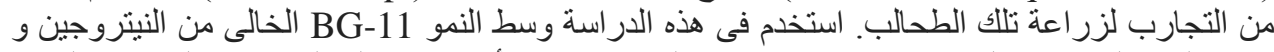

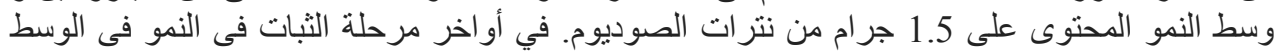

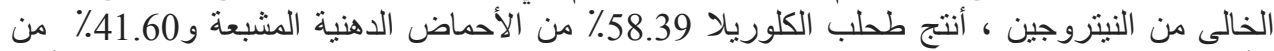

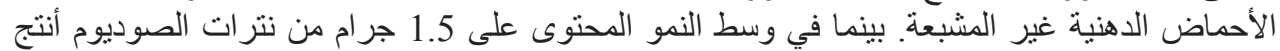

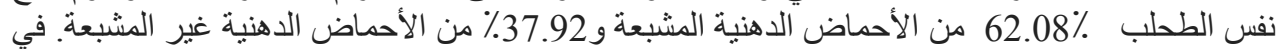

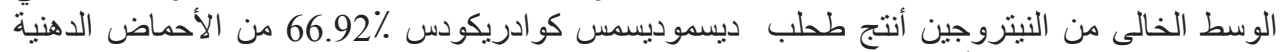

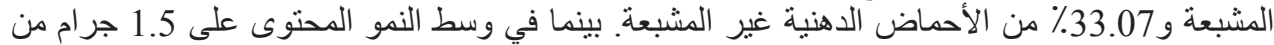

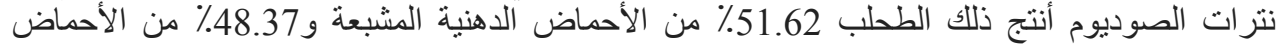

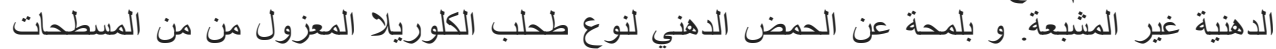

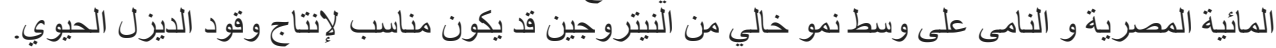

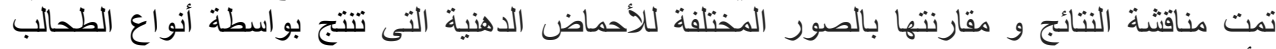

